\title{
Diez años del sistema de promoción y protección de los derechos de la niñez y la adolescencia: un balance desde el Conurbano Bonaerense
}

Advancing and protecting children and teen-agers' rights in Greater Buenos Aires municipalities: A ten-years appraisal

Javier Moro

Investigador del área de política social del Instituto del Conurbano de la Universidad Nacional de General Sarmiento.

jmoro@ungs.edu.ar javmoro@gmail.com

Fecha de recepción:

30.1.18

Fecha de aceptación:

26.5.18

\section{Resumen}

Este artículo analiza el desempeño de las nuevas áreas municipales de niñez y adolescencia en el conurbano bonaerense. Se apoya en hallazgos de una investigación cualitativa enfocada en dos municipios (La Matanza y Quilmes) para ponderar críticamente algunos aspectos del diseño, de su implementación a nivel local y de la normativa respectiva, incluyendo algunas observaciones sobre el nivel provincial en su rol de coordinación. Se argumenta que el énfasis en el eje de atención en el ámbito doméstico-familiar en desmedro de la expansión de una oferta programática de promoción y acceso a derechos plantea un alcance limitado y restrictivo de la transformación declamada en la normativa. Se concluye asimismo que las intervenciones de restitución de derechos también encuentran límites en su capacidad de funcionar bajo una lógica de corresponsabilidad. A partir de estos hallazgos, el artículo postula la adopción de una "nueva arquitectura" institucional que contemple los alcances de la política de niñez y adolescencia en el nivel 
local, la definición del problema con la que trabajan estas áreas y una mirada territorial de las políticas sociales.

Palabras clave: políticas sociales - niñez y adolescencia - derechos - conurbano - municipios.

\section{Abstract:}

This article deals with the institutional build-up of new areas for children and adolescents in municipalities of Buenos Aires Province close to Buenos Aires City. Findings of a qualitative research conducted in two municipal settings (La Matanza and Quilmes) together with an institutional analysis, enable us to critically asses some aspects in the design, regulations and implementation of policies addressed at children and the adolescent at the local level, in addition to some observations on the coordinating role performed by the provincial government's administrative agencies. According to our findings the prevalent institutional focus on the domestic-family environment in the attention of cases of human rights violations, to the detriment of the expansion of programs addressed at the promotion and access to rights, leads to a short-sighted as well restrictive view of the policy transformations aimed at by normative regulations. The interventions oriented towards the enforcement of rights also confront with limits in their capability to function under a logic of co-responsibility. An allegation is made, then, for a "new architecture" taking into account the scope of policies for childhood and adolescence at the local level together with a definition of the problem these areas deal with, and a territorial overview on social policies.

Key-words: social policies - childhood and adolescence - rights - Buenos Aires Conurban - municipalities. 


\section{Introducción ${ }^{1}$}

En la última década el gobierno de la Provincia de Buenos Aires puso en marcha la construcción de un nuevo dispositivo institucional en el marco de la ley 13298 "de la Promoción y Protección Integral de los Derechos de Los Niños". A través de esta ley se puso fin al patronato de menores que daba sustento al régimen de minoridad en la Provincia y comenzó a implementarse un nuevo modelo, llamado "sistema de promoción y protección integral de derechos" que promueve un giro conceptual y un nuevo marco de acción política, a la vez que instaló a los gobiernos locales ante un nuevo ámbito de competencias en materia de políticas de niñez y adolescencia. El conurbano bonaerense reúne un conjunto de características que, por su masividad y complejidad, lo constituyen como una región clave para dirimir la particularidad del proceso de implementación y el perfil de las nuevas áreas locales de niñez y adolescencia. ${ }^{2}$

En este trabajo se analiza este proceso, entendiendo que el mismo se encuentra en una etapa inicial con varios aspectos aun por desarrollar, pero que a la vez, justamente por eso, resulta clave en tanto instancia fundacional de una nueva institucionalidad. En tal sentido, se repasa primero una caracterización de lo que fue la institucionalidad de la minoridad, con el propósito de contextualizar el punto de partida y dar cuenta de lo que se pretende transformar. Posteriormente (apartado tres) se analiza al nuevo marco normativo anclado en derechos y particularmente la nueva ley provincial y su reglamentación, entendidas como diseño de la nueva política pública. Luego (apartado cuatro) se enfoca la nueva trama institucional establecida por la normativa que postula romper con la lógica sectorialista y selectiva de la minoridad y remite al marco de universalidad desde el cual se promueve esta transformación. El apartado cinco ubica el análisis a nivel de los gobiernos locales y la conformación de nuevas áreas de niñez y adolescencia; se plantean allí algunas tensiones entre las que destaca la tendencia a institucionalizarse como áreas de atención y protección ante derechos vulnerados, relegando la línea de promoción de derechos y el trabajo territorial. En el apartado final se argumenta que, en territorios signados por la desigualdad y la exclusión, es necesario repensar la arquitectura de las políticas sociales en base a un análisis crítico de tres aspectos entrelazados: los alcances de la política de niñez y adolescencia en el nivel local, la definición del problema con la que trabajan estas áreas y una mirada territorial de las políticas sociales. También se presentan algunas reflexiones en términos de desafios y tensiones inherentes a la problemática con la que trabajan estas áreas y a la actual coyuntura política.

Este artículo recupera algunos hallazgos y resultados de la investigación sobre el proceso de implementación de esta ley en los municipios del conurbano bonaerense. ${ }^{3}$ En su primera etapa, de carácter exploratorio, implicó entrevistas y en algunos casos observaciones directas en las nuevas áreas de niñez y adolescencia de cinco municipalidades; posteriormente se seleccionaron dos de ellas para efectuar un análisis en profundidad. ${ }^{4}$ Esta 
última etapa requirió de una metodología cualitativa de estudios de casos a partir de la construcción de una estructura narrativa elaborada en base a los testimonios de algunos actores clave que permitió construir una línea de tiempo para cada uno de los casos, donde se define el contexto particular de cada municipio, los momentos e hitos significativos y se identifican los actores, las interacciones y las acciones más relevantes (Yin 1994; Barzelay y Cortázar 2004). Cada estudio en profundidad se desarrolló con base en entrevistas semi-estructuradas con un criterio de saturación de la información, más instancias de observación directa y una revisión de estadísticas y fuentes secundarias que incluyó documentos oficiales y producciones basadas en otras investigaciones o presentaciones en ámbitos académicos. ${ }^{5}$ Vale aclarar que este artículo no desarrolla los estudios de caso en sí mismos, sino que recupera elementos empíricos y parte del análisis de la investigación para plantear una mirada más amplia sobre las implicancias del proceso de implementación de esta política en los municipios del conurbano bonaerense.

\section{El legado institucional de la minoridad}

Durante el siglo veinte, en paralelo a la escuela obligatoria, funcionó el dispositivo institucional de la minoridad dirigido a un sector de la infancia que quedaba fuera de la escolaridad y/o no tenían familias o las mismas, bajo la mirada estatal, no cumplían con las condiciones para una crianza adecuada. Este andamiaje institucional, o más precisamente este campo -en el sentido de Bourdieu (vid Bourdieu y Wacquant 1995)- se configuró por separado del saber educativo y fuertemente vinculado al saber médico (particularmente al higienismo social) y al saber jurídico penal. Así, el sentido de la infancia moderna fue asimilado al de una infancia escolarizada y en familia (alumno/a e hijo/a),mientras que el límite de esta categoría fue establecido con esa "otra" infancia que, en tanto otra, cambió de denominación y se constituyó como 'minoridad' (en buena medida una 'no infancia'). Mientras la escuela obligatoria "rescató" a la infancia del mundo adulto para producir a la "niñez normal”, el sistema de minoridad se haría cargo de disciplinar y moldear a su contraste, los menores, aquellos indisciplinados, rebeldes, o bien sobre los que sus progenitores no cumplían las funciones esperadas. El Estado se erigía así a cargo de un sector de la infancia, ya no sólo de su educación y formación, sino de su misma existencia (Moro 1997).

El sistema de minoridad emergió a comienzos del siglo pasado como heredero directo de las instituciones benéficas y de caridad ligadas a la iglesia (la mayoría para huérfanos) y en torno a la cuestión de los 'menores'. La definición de los 'menores' como problema público abreva de una mirada médico-higienista en torno a las situaciones sociales de la infancia y de una preocupación proteccionista y benevolente que debatía con -y también se apoyaba en- el saber jurídico penal muy vinculado al sistema penitenciario de adultos (Colángelo 2008). En tal sentido, confluyeron dos preocupaciones para configurar y dar sustento al problema de la minoridad, la inquietud por la niñez no 
escolarizada y la preocupación por aquellos niños y niñas que se presumía quedaban por fuera de las funciones de crianza de la familia (que según los parámetros del ideal burgués debía circunscribirse al ámbito doméstico y privado). Este sector de la infancia que aparecía por fuera de esos dos dispositivos institucionales centrales de socialización -la escuela y la familia- fue visto como un peligro efectivo o latente para el resto de la sociedad. El crecimiento de las grandes ciudades (la más notoria fue Buenos Aires) superó la capacidad de las tradicionales organizaciones de caridad y se comenzó a cuestionar la circulación de la niñez en ámbitos públicos sin la presencia de sus padres, lo que los dejaba expuestos a actividades y relaciones vinculadas al delito.

Pero esta conceptualización desde la defensa social chocaba con la mirada moderna de la infancia en tanto ser dependiente e inacabado que requería protección, cuidado y la separación del mundo adulto. De hecho en simultáneo surgió un fuerte reclamo por los niños que en las cárceles recibían el mismo trato que los adultos y compartían las mismas celdas. Respecto a esta cuestión carcelaria, a fines del siglo XIX en los Estados Unidos surgió un movimiento humanista que reclamaba tribunales especiales para los menores, esta corriente fue hegemónica en el saber jurídico y tuvo gran influencia en toda la región latinoamericana para la construcción del sistema tutelar. ${ }^{6}$

Esta convergencia entre control y protección fue la amalgama ideológica que dio forma a los institutos de menores -también llamados orfanatos o reformatorios- y han sido en el siglo pasado la institución insignia del modelo de la minoridad (cfr. por ejemplo Bellof 2009; Larrandart 1998; Zapiola 2013). Se trataba de instituciones totales (Gofman 1972) de encierro, o de internación en su denominación más sutil, en el sentido que todo sucedía "intramuros": reproducían en su interior las opciones de educación, la formación de oficios, los espacios de recreación, la atención de la salud y los lazos sociales. En esos contextos de encierro, la construcción de un proyecto de vida aparece íntimamente relacionada con esta situación intra-institucional que recorta el horizonte de posibilidades a los límites de la misma institución, sin posibilidades de construir lazos de arraigo. ${ }^{7}$ A su vez, estas instituciones funcionan con frecuencia como ámbitos de socialización (prematura) con otros niños/as y adolescentes con una (mayor) trayectoria en los dispositivos de la minoridad y/o con recorridos biográficos en actividades delictivas (que en esos espacios suele funcionar como una credencial de estatus y respeto entre pares).

Estas políticas tendieron a configurar subjetividades tuteladas (en el sentido de Costa, Mara y Carigliano 2000) a través de intervenciones que, por un lado, situaban a los sujetos a disposición de un juez hasta la mayoría de edad y, a su vez, promovían un efecto de estigmatización que funcionaba como profecía de autocumplimiento (Gofman 1987), marcando un derrotero de institucionalización en lugares de encierro que, posteriormente en la adultez, habría de continuar en el sistema penitenciario. 
Este efecto estigmatizante de las instituciones de minoridad se sustentaba en una operatoria propia que conviene desagregar de sus efectos. Para desentrañar esa operatoria es necesario detenerse en las categorías que utiliza para definir a su población objetivo. ${ }^{8}$ Prácticamente todas las legislaciones de menores de América Latina le otorgaron al juez (o su similar, consejero, secretario, asesor, etc.) el mandato de actuar como buen padre de familia, y con ello amplios poderes para disponer de la vida y básicamente de la libertad de los "menores". Las políticas de minoridad actuaban selectivamente a través de definiciones ambiguas, particularmente la de abandono moral o material según lo definía la ley 10.903 en el caso argentino. La mirada selectiva en la aplicación de estas normativas estuvo fuertemente orientada por dos ideas que se complementaban: defensa social y prevención. La primera corresponde a un argumento común a todo el cuerpo del derecho penal, en torno a la idea de que es necesario defender a la sociedad de sus componentes negativos y que se debe aislar la parte 'enferma' o 'desviada'. La segunda es más específica del campo de la minoridad y tiñe la interpretación de la protección. Se entiende que es necesario intervenir cuanto antes para evitar que los "menores" se conviertan en delincuentes, para ello hace falta reformarlos y sacarlos de un ambiente dañino (ya sea la calle, la familia o ambos). Nuevamente el discurso de protección no sólo encubre el control, sino que lo incrementa; el menor pasaba a ser visto como delincuente o bien como potencial delincuente, por lo tanto se convertía en peligroso o en situación de inminente peligro o en riesgo social y se daba lugar a intervenciones tutelares por motivos de índole social (en un sentido amplio que refiere a aspectos socioeconómicos, psicosociales, socio ambientales y/o familiares).

Con el advenimiento de una nueva concepción que declama por una sola categoría de infancia y, a la vez, la reconoce en tanto sujeto de derechos, se abre una nueva etapa que redefine y replantea el modelo institucional.

\section{El giro conceptual y normativo para construir un nuevo modelo institucional}

La Convención Internacional de los Derechos del Niño (CIDN) planteó un nuevo marco jurídico que promovió un giro conceptual para las políticas públicas: el reconocimiento de los niños como sujetos de derecho. ${ }^{9}$ A partir de ella se explicitaba una ruptura con la tradición tutelarista del sistema de minoridad y se promovía una reorientación de las intervenciones y de las políticas. Se redefinió la concepción de la infancia, promoviéndose una categoría abarcadora que interpela a una sola infancia que deja de ser considerada como mero objeto de disciplinamiento, protección, beneficencia y/o control. La niñez es reconocida como sujeto con iguales derechos más una consideración especial de acuerdo al momento de desarrollo en que se encuentra.

Esta reconceptualización o re-enmarque de la problemática se postula para todas las políticas públicas dirigidas a la niñez pero traía un cuestionamiento explícito y más 
directo con respecto a las áreas asistenciales de las políticas sociales, particularmente hacia las intervenciones tutelares del Estado (y hacia allí va el foco de este trabajo). ${ }^{10} \mathrm{Al}$ respecto, vale una muy breve contextualización para recordar que esta mirada crítica venía gestándose con anterioridad de la mencionada CIDN.$^{11}$ Por un lado, en el plano regional e internacional, los mismos organismos defensores de la niñez, con Unicef como principal impulsor, eran muy críticos desde fines de los años setentas de las macro-instituciones de encierro. Por su parte, en el plano nacional -más específicamente en la zona metropolitana de Buenos Aires- desde el retorno a la democracia algunas áreas de minoridad promovían un cambio en la lógica de intervención a través de la "gestión asociada" con las ONGs ${ }^{12}$ en calidad de hogares con vivenciales de puertas abiertas (con formatos múltiples) y se generaron nuevas modalidades de trabajo con la población de niños/as en calle (operadores en calle y centros de día, entre otros).$^{13}$ La atención a la niñez en situación de calle fue uno de los principales asuntos en la agenda de estas áreas desde fines de los años ochenta y durante toda la década siguiente. En muchos casos, estas iniciativas recuperaban experiencias territoriales desarrolladas por organizaciones sociales (muchas de ellas vinculadas a organismos de derechos humanos, iglesias u organizaciones religiosas, a organismos de cooperación internacional y a entidades comunitarias) y se (auto)denominaban como programas y políticas alternativas ya que iban en contrapunto al patronato y a las intervenciones de tipo punitivas. ${ }^{14} \mathrm{La}$ continuidad de esas propuestas fue la base de los programas estatales socioeducativos que posteriormente habrían de desarrollarse principalmente en las áreas sectoriales de educación y desarrollo social.

En cierta medida, durante varios años se profundizó un proceso de construcción estatal bifronte en las áreas sociales para la infancia: por un lado, con una nueva oferta de programas socioeducativos -abarcaban desde el trabajo en calle al trabajo en pequeños hogares de puertas abiertas, centros de día y centros territoriales con ofertas variadas en zonas postergadas- que apostaban a una modalidad de trabajo basada en la construcción de un vínculo de confianza que permitiese consolidar a los referentes adultos y a grupos de pares en torno a proyectos o actividades significativas (a la par de este encuadre con respecto a la población se promovía un trabajo organizacional en red)-.${ }^{15}$ Pero, a la vez que se comenzaba con ese desarrollo incipiente, se mantenía un campo de intervenciones (si bien más acotado) que continuaba rigiéndose bajo los criterios y la lógica del modelo tutelar (en la mayoría de las jurisdicciones los institutos de menores siguieron vigentes y los actores judiciales mantuvieron un papel protagónico a través de intervenciones tutelares en la mayoría de los casos ya que el cambio conceptual permeó más lentamente el poder judicial).

En el plano normativo fue recién en el año 2005 que Argentina derogó la ley de patronato (a través de la Ley nacional 26.061). Esta nueva normativa (que ya tenía antecedentes de leyes en algunas jurisdicciones provinciales) ${ }^{16}$ ponía un límite a la institucionalización en lugares de encierro a partir de situaciones asistenciales y apuntó a la construcción de un sistema amplio e intersectorial de protección y promoción de derechos. En el plano específico de las acciones estatales de tutela el cambio normativo 
promovía una acción más acotada (como último recurso) y una transformación de la lógica de esas prácticas tutelares.

En ese contexto, el gobierno de la Provincia de Buenos Aires inició, a través de la Ley 13.298, ${ }^{17}$ un proceso de construcción de una nueva institucionalidad en torno a la creación de un sistema de promoción y protección de derechos de la niñez y la adolescencia:

(...) el principal objetivo de la política de infancia debe ser la crianza y desarrollo de los niños dentro de su familia y, sólo en última instancia, como medida de protección, de carácter excepcional y provisional (... $)^{18}$

En esta línea el ejecutivo provincial planteaba que la ley buscaba evitar la institucionalización y la judicialización de situaciones de pobreza, que era uno de los aspectos más cuestionados del modelo de minoridad.

\section{La nueva y compleja trama institucional en la Provincia de Buenos Aires}

La ley 13298 y su decreto reglamentario generaron una nueva trama de institucionalidad política ${ }^{19}$ en torno a la cual en este apartado serán destacadas tres cuestiones que considero críticas: 1) aspectos novedosos pero inciertos respecto a la coordinación política y técnica del nuevo sistema a partir de un actor organizacional sin antecedentes en la materia; 2) una articulación compleja entre el nivel provincial y el local, con responsabilidades y alcances ambiguos en algunos aspectos de la normativa; 3) más una implementación con amplio margen de acción del nivel local y un sesgo hacia la atención de situaciones de vulneración de derechos, relegando la expansión de una oferta programática de promoción y acceso a derechos en los territorios.

Con respecto al primer señalamiento, la ley presenta una ambiciosa propuesta de un esquema integrado entre las diferentes áreas sectoriales que conforman un sistema articulado de promoción y protección de derechos cuya principal instancia de coordinación y articulación de políticas pasaba por la (flamante) Comisión Interministerial. En este esquema se (re)posicionaba al ministerio de asuntos sociales (en ese momento de Desarrollo Humano y posteriormente de Desarrollo Social y después Secretaría de Niñez y Adolescencia) como autoridad rectora para

promover el cambio de prácticas y de funcionamiento de los organismos de gobierno de la Provincia... tiene como objetivo articular las acciones entre los distintos ministerios y optimizar los recursos del Estado provincial destinados a la atención de los niños y las familias. ${ }^{20}$ 
A esta Comisión se le encomendaban dos elementos claves para la función de coordinación: la elaboración del plan de acción y la gestión de la información. El plan de acción refiere a un rol político para llevarlo a cabo, lo que requiere capacidad de liderazgo y de coordinación para evitar que se transformen en un espacio (la propia comisión) o un documento (el plan) meramente formales (cfr Cunill Grau, Repetto y Bonzo 2015). Por su parte, la gestión de la información hace referencia a un soporte técnico que debe generar insumos estratégicos para ejercer la coordinación y conducción del plan. En este ítem destaca la creación del Registro Estadístico Unificado de la Niñez y Adolescencia (REUNA), tal vez el aspecto de mayor desarrollo durante este período (sobre todo en términos relativos si se compara con el resto de las jurisdicciones o con la propia Secretaría Nacional de Niñez y Adolescencia (SENAF). ${ }^{21}$

La creación de esta Comisión Interministerial, que se presentaba como un aspecto novedoso en el diseño, ${ }^{22}$ llegó a formular un plan provincial (Plan Provincial "Los pibes del Bicentenario"), ${ }^{23}$ pero su implementación tuvo serias dificultades de liderazgo por parte del área social, históricamente más vinculada a la asistencia y a la gestión de las instituciones de minoridad, con escasa inserción territorial y con menos recursos (financieros y organizacionales) que las áreas con más presencia -como educación y salud- y lógicas institucionales propias. Para compensar esto hubiese sido necesario un respaldo político del máximo nivel, capacidades propias de liderazgo y un flujo de recursos adicionales para construir una autoridad con capacidad efectiva de coordinación y de gestión que rebase las lógicas e intereses de cada sector. Sin este "plus" la comisión interministerial fue quedando relegada como una instancia con escasa incidencia. ${ }^{24}$

Con respecto a la articulación provincia-municipios, es importante tener en cuenta que la ley tuvo la peculiaridad de aprobarse con una cláusula de adhesión a través de un convenio por parte de las municipalidades. ${ }^{25} \mathrm{Si}$ bien varias municipalidades fueron inicialmente reacias a la firma por la falta de recursos adicionales, con el transcurrir del tiempo fueron firmando (en algunos casos se contempló tanto la cuestión conceptual como la política con respecto a la disputa con los actores judiciales). ${ }^{26}$ Esa cláusula destrabó la resistencia de algunas municipalidades del conurbano en torno a la creación de un sistema nuevo que le daba nuevas competencias y responsabilidades a esas instancias de gobierno sin la inyección de recursos adicionales.

Al respecto, no todas las municipalidades cuentan con presupuesto propio además del que ingresa por el Fondo provincial mencionado anteriormente. Una cuestión aún más preocupante es el manejo de esos fondos dentro de cada municipalidad. En un relevamiento realizado en el año 2012, sólo "el 61\% de los municipios declaró que cuenta con una asignación presupuestaria destinada al diseño, implementación y evaluación de la política de niñez a nivel local” (SNyA - Pharos - Unicef, 2012). 
El nuevo diseño institucional plantea un esquema particularmente complejo para las estrategias que implican medidas excepcionales ${ }^{27}$ donde, a la doble injerencia entre áreas administrativas y judiciales -que ya planteaban tensiones recurrentes en el anterior modelo de minoridad- se agrega la descentralización hacia los niveles municipales. De este modo, se incorpora una (potencial) tensión recurrente entre el servicio local y el servicio zonal. ${ }^{28}$ Ambos niveles jurisdiccionales quedan inscriptos bajo el sistema de protección integral como instancias formales en el nuevo dispositivo administrativo que se establece para la protección ante derechos vulnerados. Los nuevos servicios locales nacieron con una doble dependencia: por un lado se trata de servicios municipales, con recursos humanos, presupuesto e inscripción institucional en la orgánica del municipio; mientras que en tanto servicios del sistema del protección deben reportarse al Servicio Zonal en calidad de organismo desconcentrado del Ministerio de Desarrollo Social. Además los servicios locales están obligados a informar a la instancia judicial (Juzgado de Familia) por el control de legalidad de las medidas, a la vez que en muchas situaciones deben dar respuesta a directivas del Asesor de Incapaces del Ministerio Público. De este modo, en una situación concreta donde se pongan en juego decisiones sobre la vida de un niño/a pueden involucrarse varios actores desde diferentes ámbitos institucionales: Servicio Zonal, Servicio Local, Juzgado de Familia y Asesor de Incapaces (o fiscal si se tratase de una infracción a la ley penal) más otros actores institucionales que pudiesen estar vinculados (escuela, centro de salud, organización social o comunitaria, etc.). De hecho, a partir de un conflicto entre un servicio local y un zonal, intervención judicial mediante con pronunciamiento de la corte suprema provincial, se cambia la reglamentación y se reconoce la potestad del servicio local para tomar la medida sin necesidad de aval del servicio zonal.

Por tanto, la coordinación entre estos actores para establecer y acordar criterios, tiempos y decisiones plantea escenarios de gran complejidad donde los costos, en el sentido de marchas y contramarchas, superposiciones, etc., pueden recaer en los propios sujetos a los que se busca restituir derechos vulnerados. Asimismo, resulta recurrente la tensión que se genera entre los servicios locales que pueden decidir medidas excepcionales y la agencia o repartición provincial que dispone de las vacantes (generalmente escasas) en instituciones propias y en las ONGs con las que se han celebrado convenios. ${ }^{29} \mathrm{Tal}$ como es comentado por la coordinadora de una de las oficinas de un servicio local:

vos tomabas la medida de abrigo y la tenías que girar al Zonal, a la Asesoría de Menores y al Juzgado de Familia; el Zonal lo que hacía era evaluarte esa medida de protección y en el caso de necesitar una vacante, te habilitaban alguna vacante de la que ellos disponen... asesoran y controlan la legalidad y el juzgado también, eso tiene tiempos, cada tanto tenés que prorrogar... la asesora con el tiempo puede convocar al niño e indagar cómo va la situación, lo 
estratégico es que el Servicio Local con la Asesoría y el Zonal trabajen en conjunto $y$ sin demasiado conflicto. (entrevista a licenciada en política social, ex coordinadora de una de las oficinas del servicio local de la Municipalidad de San Martín).

Finalmente, el tercer aspecto crítico refiere al plano local, donde efectivamente se dieron los cambios más significativos en cuanto a la conformación de áreas de niñez y adolescencia. La mayoría de las municipalidades tenía muy escaso desarrollo institucional en la materia y con la nueva normativa debieron asumir nuevos roles y funciones en políticas sociales para la infancia y la adolescencia. Sin embargo, si bien la misma normativa planteaba un horizonte ambicioso de integración intersectorial, a escala local el mismo diseño fue mucho más preciso en la conformación de los servicios como instancia de atención ante denuncias y detección de situaciones de vulneración de derechos, donde llegaba a precisar el perfil requerido del equipo profesional ${ }^{30}$ mientras que sólo enunciaba de manera genérica las opciones de construir una oferta programática relativa a la promoción de derechos. ${ }^{31}$

Ahora bien, estas nuevas áreas municipales de niñez y adolescencia (que incluyen a los servicios locales) son instancias de interacción directa con la población y, por tanto, prototípicas de lo que la literatura especializada ha caracterizado como burocracias a nivel de calle (por ejemplo Lipsky 1971). Se trata de espacios que gozan de cierta autonomía relativa que puede volverse problemática en términos de discrecionalidad en la acción o inacción (en un sentido negativo pueden generar desvíos en cuanto a los objetivos programáticos y la orientación de las acciones, o bien demorar u omitir intervenciones que en estos casos pueden implicar situaciones de emergencias) pero, a la vez, pueden apuntalar y potenciar la incidencia territorial de las políticas (de manera frecuente en el plano de la implementación suelen adaptarse propuestas para darles viabilidad y pertinencia, o bien, se generan acciones que no estaban previstas por la planificación centralizada). A estas características propias del nivel de los efectores hay que adicionarle el tipo de problemática a la que se enfrentan que implica un tipo de modalidad no estandarizada en las intervenciones. Por tanto, la impronta del nivel local se torna particularmente relevante y requiere situar allí el foco del análisis.

\section{Aspectos críticos en el proceso de implementación a nivel local}

La 'bajada' del nuevo modelo trasladó hacia el nivel local una tensión entre constituirse como un servicio de atención a la demanda (y/o las denuncias) de situaciones de vulneración de derechos (en su amplia mayoría referidos al ámbito familiar) o bien aspirar a una construcción más amplia que promueva también una oferta programática de promoción de derechos a escala territorial (algo más en línea con la creación de un sistema). Se trata de una cuestión clave que, en buena medida, marca el derrotero de las áreas locales de niñez y adolescencia. 
Desde el nivel provincial se puso énfasis en la línea de acción de las intervenciones (singulares) de restitución de derechos que se vinculan más linealmente con el dispositivo de minoridad que las antecede -a la vez que intentan transformarlo-. Tal como lo expresa el testimonio de esta ex funcionaria:

“(...) Era un tema muy grueso... en ese momento (2007/08) la idea del equipo era trabajar la promoción. Pero hoy creo que no se podía, no teníamos tan clara la envergadura del tema, fue un diagnóstico equivocado que no contemplaba estar parado con un poder judicial que traccionaba en contra... y sin oferta ni recursos para programas de promoción... pero lo otro [las situaciones singulares de intervención] se te viene encima y la lógica del caso te atrapa... y hubo mucha conflictividad en los institutos".

(Entrevista a ex asesora de Ministro).

Ese primer intento de un énfasis en la promoción quedó trunco e implicó un cambio en la persona y el perfil de la cartera provincial al año de inicio de la implementación efectiva de la ley.

Se plantean en consecuencia modificaciones en las intervenciones en cuanto a los criterios y medidas adoptadas, así como en los circuitos y procedimientos, aunque sosteniendo (dada la complejidad y heterogeneidad que originan estas intervenciones) la modalidad de atención por casos. La mayoría de las municipalidades del Gran Buenos Aires iniciaron sus respectivos procesos de construcción de estas áreas de niñez y adolescencia respetando este énfasis en la atención y restitución de derechos. Aunque hay Municipalidades que intentaron y/o aun intentan construir un sistema más amplio y no acotado a la atención de derechos vulnerados $^{32}$ o incluso que plantearon explícitamente un diseño por etapas que intentaba una construcción programática más amplia en el territorio antes de constituir el servicio local. ${ }^{33}$

Según un relevamiento del año 2014

El 30\% de los municipios, reconoce no ejecutar programas propios destinados a la atención de $N N y A$ [niñas/os y adolescentes], lo cual evidencia una... alta dependencia de los recursos provenientes del gobierno nacional y provincial para atender la demanda de este sector de la población. (SNyA - UNICEF - Pharos, 2015:20).

A la alta dependencia del financiamiento provincial y nacional puede adicionarse en algunos casos (casi el 40\% de este relevamiento) que las áreas de niñez y adolescencia no 
disponen de partidas presupuestarias propias, lo que implica una dependencia interna en el propio gobierno local (negociación y/o disputa según el caso y según la coyuntura) con las máximas autoridades políticas o con el área de finanzas. Tal como comenta el funcionario a cargo del área de niñez y adolescencia en La Matanza:

(...) lo que pasa ahí es que el convenio de adhesión no especifica que el Fondo es para el servicio local o para el área de niñez y adolescencia, sino que se estableció que el $50 \%$ era para niñez y entonces si hacés una salita es para niñez, si mejorás una plaza, etc. también.

(Entrevista a Director de Niñez y Adolescencia La Matanza).

Al respecto, vale una mención al otro estudio de caso analizado en la investigación, donde la funcionaria reconoce que tuvo un importante aval político del intendente y un amplio margen para la toma de decisiones pero que esa autonomía también se debió a la disponibilidad de recursos:

(...) mi primera pelea fue por los fondos al interior del municipio, este punto es clave y no en todos los casos las áreas de niñez los controlan de manera directa y la Provincia no logra supervisar este proceso.

(Entrevista a ex Secretaria de Desarrollo Social - Quilmes).

Pero tal vez el dato más preocupante del mencionado sea que mientras (prácticamente) la totalidad de los municipios realiza acciones de atención directaante situaciones singulares de derechos vulnerados, apenas la mitad implementa programas de promoción:

"el 99\% de los referentes consultados manifestó que implementa acciones y prestaciones referidas a la resolución de casos puntuales a través de la asistencia directa en sus municipios. En tanto que el $51 \%$ realiza también políticas promoción de derechos destinadas a NNyA"

(SNyA - Pharos - UNICEF 2015:22).

Lo dicho pone en evidencia lo acotado de la pretendida transformación. Aún así, en su versión más restringida, la propia tarea de crear un servicio local constituyó un desafío de gran complejidad en términos de profesionalizar las intervenciones y cambiar la lógica de la intervención. Tal como comenta la funcionaria a cargo del área: 
Eran militantes no profesionales con expedientes tutelares casi policiales y ellos venían y te contaban como muy contentos porque eran muy comprometidos... muy código de barrio que le dicen que fulanita le pega a los chicos y llaman a ver qué pasa.

(Entrevista a ex Subsecretaria de Niñez,Municipalidad de Quilmes).

A la vez, la incorporación de las nuevas competencias municipales implicó una reconfiguración del escenario institucional preexistente que requirió acuerdos entre los actores implicados y una nueva "ingeniería" que en algunos casos resultó bastante caótica, tal como lo expone una de las profesionales de un servicio local:

El primer trabajo fue con justicia, los tribunales de menores se iban y nos tenían que pasar la posta. Hubo encuentros, acuerdos, empezamos a fijar nuestras competencias acordes a la ley y a la CDN. Con algunos juzgados se trabajó bien, con otros no hubo acuerdo. El traspaso de 'casos', 'situaciones', fue mucho, excesivo. La directora de ese momento se sintió avasallada...

(Entrevista a abogada del Servicio Local, La Matanza).

Por su parte, en los territorios la apertura de una nueva oferta -en este caso un servicio de atención ante situaciones urgentes de derechos vulnerados en la niñez- captó una alta demanda latente, tal como señala este funcionario provincial:

(...) cuando vos ponés un servicio local levantás mucha demanda... y al inicio hubo dos municipios ${ }^{34}$ que firmaron y después, cuando vieron la demanda, renunciaron al convenio... tiempo después recompusimos la relación y volvieron a tener (Servicio) Local en ambos casos"

(Entrevista a ex Subsecretario de Niñez y Adolescencia de la Provincia de Buenos Aires).

Del relevamiento realizado a través de entrevistas con actores de las nuevas áreas de niñez y adolescencia en algunas municipalidades del conurbano ${ }^{35}$ las mayores dificultades se refieren a los siguientes items:

- Escasa coordinación y presencia del nivel provincial. ${ }^{36}$

- Déficit de financiamiento tanto para ampliar 
equipos como para expandir la oferta programática (servicios y programas). Además del porcentaje del fondo de asistencia social directa que debe destinarse a la gestión municipal de políticas de niñez y de los hogares de convivencia con los que se celebraron convenios, el gobierno provincial financia a organizaciones sociales (principalmente a través de las Unidades de Desarrollo Infantil) ${ }^{37}$ pero su cobertura carece de un alcance masivo. ${ }^{38}$

- Reconocen que hubo capacitaciones desde el nivel provincial -sobre todo al inicio- pero que no se sostuvo como un proceso continuo que acompañe la puesta en marcha y que posteriormente trabaje sobre las intervenciones concretas.

- Al respecto, la elaboración de protocolos y guías de procedimientos suele presentarse como un aspecto crítico o aun deficitario. Aun cuando la Secretaría Provincial ha elaborado guías de procedimientos y modelos de actas de actuación, en algunos casos mencionaron la elaboración propia de protocolos; eso implica que cada servicio local podría tener su propio procedimiento, potenciando una diversidad de modalidades y criterios de intervención.

- La dificultad para consolidar (buenos) equipos técnico-profesionales emerge como otro común denominador de estas áreas. Esto se relaciona con una falta de jerarquización, modalidades contractuales precarias, inestables y de bajas remuneraciones. La alta rotación es frecuente en estas áreas donde la propia problemática con la que trabajan implica un efecto de desgaste y saturación.

- La falta de vacantes para las medidas excepcionales de protección suele constituir un recurso crítico que potencia la tensión entre el servicio zonal y el local (no sólo por lograr una vacante sino también en cuanto a los tiempos, la modalidad y tipo de institución que se requieren, la ubicación, entre otras cuestiones sensibles para las estrategias de intervención de esta índole).

- Además en este ítem se pone de manifiesto un déficit del nivel provincial tanto en la oferta propia $^{39}$ como en materia de financiamiento (lo que el estado 
paga por cada niño/a alojado en una institución $)^{40}$ y en las capacidades estatales para la regulación, supervisión y asistencia técnica con las organizaciones que intervienen a través de convenios. ${ }^{41}$

- Se observa escasa articulación entre los equipos que trabajan en el territorio vinculados a servicios y programas de promoción de derechos, con los equipos de atención de derechos vulnerados que trabajan en sedes administrativas. Hay algunas iniciativas que han apuntado a desarrollar modalidades de acompañamiento como estrategia de intervención ante derechos vulnerados, lo que implica un trabajo territorial (con instituciones, referentes barriales y programas de promoción) y una acción de seguimiento y de construcción de un vínculo con el sujeto en cuestión. ${ }^{42}$

- Este último ítem se relaciona con las dificultades para un trabajo conjunto con otras áreas sectoriales. El cambio de una lógica de derivación a una lógica de corresponsabilidad requiere el involucramiento, el compromiso y un marco de trabajo común de las diferentes áreas y jurisdicciones para desarrollar capacidades institucionales de funcionamiento como redes de sostén en las situaciones críticas. ${ }^{43}$ Con frecuencia las mayores dificultades de articulación bajo una nueva lógica refieren a las áreas sociales de mayor presencia territorial como educación y salud, aun cuando suelen ser estas mismas áreas con las que deben coordinar con mayor frecuencia. ${ }^{44}$ En este ítem destaca la experiencia inicial del Municipio de La Matanza, donde el sistema de protección y promoción de derechos -incluyendo al servicio local- se creó en el ámbito de la jefatura de gabinete (años después pasó a la Secretaría de Desarrollo Social) lo que le dio un peso político en el momento fundacional que resultó clave, tal como lo expresa quien fuera el funcionario promotor de la iniciativa:

(...) para involucrar a todos los sectores... yo tenía que pedir como jefe de gabinete que atiendan a un chico en un hospital, o convocar a una inspectora de educación, 
había que romper la lógica de nichos, de dominios y había que hacerlo desde un lugar de autoridad para implantar la nueva lógica, no se podía desde Desarrollo Social.

(Entrevista a ex Jefe de Gabinete de la Municipalidad de La Matanza).

- Lo que puede considerarse un avance en términos institucionales y un salto cualitativo en capacidades de gestión es la construcción de un sistema de información -el REUNA- (inexistente hasta entonces en la anterior institucionalidad de la minoridad) que, incluso, en algunos casos ha colaborado fuertemente a organizar los procedimientos de intervención, así lo indica una de las profesionales de un servicio local: "nos fue de gran utilidad porque nos ordenaba los tiempos de cada intervención y nos ayudaba al seguimiento de las mismas". ${ }^{45}$ Esta función adicional del REUNA habla también del déficit señalado en materia de formación y de elaboración de protocolos y criterios de intervención. Sin embargo, no todos los servicios locales lo cargan y suelen tener su propio sistema de registro. En algún caso el planteo tenía que ver con una tensión de carácter político o de disputa de recursos (pedidos de equipamiento y de conectividad) pero también con un límite de la base del REUNA que no incorpora información de otras intervenciones sociales con esa familia; ${ }^{46}$ este punto resulta relevante si se promueve una acción más articulada con otras áreas.

- Otro aspecto central en el cambio de lógica de las intervenciones es la incorporación de la voz del niño. Al respecto, los testimonios recogidos en los servicios locales dan cuenta de procedimientos donde se busca dar entidad a la opinión de los sujetos involucrados para establecer la estrategia a seguir, sin embargo, en muchas de las situaciones relevadas esta modalidad no alcanza a plasmarse en términos de procedimientos o protocolos institucionalizados. ${ }^{47}$ El registro del relato del niño/a y/o adolescente requiere desarrollar una aguda capacidad de escucha 
por parte de los equipos profesionales que pondere el contexto particular de cada situación y sostenga el foco de restitución de derechos en base a criterios y pautas generales de intervención.

- La gobernanza de estas áreas se construye con actores territoriales. Aun cuando algunos municipios construyeron más oferta programática propia en territorio, la presencia de organizaciones comunitarias, ONGs y aquellas vinculadas a las iglesias (como Caritas) resulta clave para construir una red de actores territoriales (y además implica un reconocimiento al trabajo de esas organizaciones que en muchos casos se constituyen como referentes y lugares de pertenencia para la niñez y adolescencia en los barrios). En este ítem en los dos municipios seleccionados para estudios de casos hubo variantes interesantes: en La Matanza la creación de un Consejo Municipal por los derechos dela niñez y la adolescencia es anterior a la creación misma del sistema local de protección y promoción (data del año 2001 y es una instancia reconocida por las organizaciones territoriales del municipio y a partir de la cual se fue eslabonando el sistema local); por su parte, en Quilmes se desarrollaron mesas de gestión barrial como instancias amplias de interlocución con la Secretaria de Desarrollo Social, donde emergían muchas cuestiones que referían a la niñez y la adolescencia en los barrios y donde se acordaban y/o se validaban nuevas iniciativas para el territorio. ${ }^{48}$

Esta breve revisión de la implementación en el nivel local pone en evidencia que para construir un entramado de actores estatales y sociales, que actúen en red, en la promoción de derechos se requieren recursos y la expansión de una oferta programática a escala territorial acorde para incidir efectivamente en las condiciones de vida y en el acceso a derechos (básicos) de toda la niñez y la adolescencia-cuestión particularmente relevante en los barrios más postergados del conurbano bonaerense-. En contrapunto, el proceso analizado muestra una falta de recursos que se retroalimentó con un rol bastante desdibujado en términos de coordinación política y técnica por parte del ejecutivo provincial; lo que devino en una escasa incidencia para construir una lógica intersectorial y potenció una gran heterogeneidad a nivel municipal. 


\section{Reflexiones finales: ¿mejorar lo que está o construir una nueva arquitectura?}

Más que repasar las dificultades y obstáculos en un proceso de implementación que -si bien ya lleva una década- aún podemos considerar como relativamente reciente en términos de construcción institucional, interesa repensar la cuestión de fondo con respecto a la política en general o, como se autoproclama, la creación de un sistema de protección y promoción de derechos. Para ello se proponen algunas reflexiones que giran en torno a tres cuestiones entrelazadas: los alcances de la política de niñez y adolescencia en el nivel local, la definición del problema con la que trabajan estas áreas y una mirada territorial de las políticas sociales.

\subsection{Acerca de los alcances}

El cambio de la vieja matriz institucional fue impulsado con aspiraciones más amplias que el universo acotado al eje de protección y restitución de derechos vulnerados. Las nuevas normativas, la ley provincial 13.298 y la ley nacional 26.061 bajo el paragüas de la Convención Internacional de los Derechos del Niño (CDN), promueven una mirada política de promoción y accesibilidad de derechos para todos los niños y niñas por igual. La construcción de igualdad como anhelo para cualquier perspectiva de política anclada en un enfoque de derechos supone pensar cómo lograr la accesibilidad a los derechos para todos los sectores de la niñez a través de servicios y de una oferta programática de calidad a escala territorial. Se trata de un planteo lógico donde la restitución opera como un conjunto de intervenciones singulares dentro de un esquema más amplio que propone, se orienta y -en el mejor de los casos- construye universalidad en el acceso a derechos. ${ }^{49}$

Entre la protección y la promoción, el "sistema" presenta un sesgo hacia la primera función en desmedro de la segunda. Esto tiene relación directa con el legado institucional del dispositivo de la minoridad y en tal sentido puede constituir una línea que, aun rompiendo modalidades de intervención, mantenga el sesgo tutelarista y selectivo que caracterizó a esas políticas sectoriales. Esto último pone en cuestión la retórica de una sola infancia y nos devuelve la pregunta si efectivamente se logró desmontar la categoría "menores“. Uno de los mayores desafios para esta nueva política es que no se limite sólo a suplantar un procedimiento judicial por uno administrativo -esto se relaciona con el dilema de superar la lógica de la emergencia que plantea el "caso a caso"-. Muestra es que para ello se requiere modificar el eje prioritario de las intervenciones, que las acciones de promoción tengan efectivamente más peso que las de protección y que la articulación entre ambas líneas de acción se constituya como modalidad habitual para dirimir las estrategias de intervención. Para ello se requiere comprender la envergadura del cambio y ser consciente de los riesgos de replicar la institucionalidad preexistente. Esto implica claridad en los objetivos políticoinstitucionales en juego y -en un nivel más operativo- un uso estratégico de los tiempos de implementación de estas políticas a nivel local. 
Esto último refiere a que la construcción de esta nueva institucionalidad en los gobiernos locales no se instituye como un proceso reversible, el orden de los factores (los tiempos, los énfasis, los modos, las prioridades de agenda, la lógica y el sentido de la acción) altera el producto. No se llega desde lo singular (del caso a caso) a la universalidad e integralidad de las políticas sociales para la niñez y adolescencia. Si se renuncia a la función de promover el acceso a derechos se está convalidando el estado de situación actual ya que se termina por abordar sólo las problemáticas desde sus síntomas más extremos a través de intervenciones que -en un plano social más amplio- no dejan de ser paliativas.

\subsection{El peso de la definición del problema}

En el momento fundacional de creación de las áreas municipales de niñez y adolescencia esta impronta cobra especial relevancia y refuerza la particularidad en torno a la definición del problema.Ya sea por el ámbito de competencia y de recursos disponibles o por el sesgo disciplinario (profesional), las acciones de los equipos abocados a la protección y restitución de derechos tienden a subsumir los problemas a la esfera doméstico-familiar, desvinculando estas situaciones de un eslabonamiento más amplio de vulneraciones (y de violencias) que atañen al sector poblacional con el que mayoritariamente trabajan. Por ejemplo, muy dificilmente los servicios locales generen acciones de exigibilidad de derechos socioeconómicos más amplios (lo que podría poner a los propios servicios locales en tensión con otras áreas sectoriales del gobierno municipal o con otros niveles jurisdiccionales de gobierno). Este recorte del problema corre el riesgo de despolitizar (y por tanto implícitamente naturalizar) una situación de desigualdad persistente y de violencia estructural que condiciona fuertemente el ámbito doméstico-familiar de esos sectores y, por tanto, rebasa el ámbito de intervención siempre acotado de la emergencia asistencial (Fraser, 2001:141). ${ }^{50}$

El enmarque del problema también incide en un recorte de especialistas en infancia que llamativamente no coordinan ni articulan con las áreas de género o mujer para la atención de situaciones de violencia que suelen tener en calidad de víctimas tanto a niños/as como a las madres (en un eslabonamiento de violencias de género e intergeneracionales) y, además, constituyen el mayor porcentaje de situaciones atendidas. ${ }^{51} \mathrm{La}$ Municipalidad de Morón presentaba una experiencia interesante en este ítem al unificar los equipos de atención en una de las Unidades de Gestión Comunitaria (UGC). ${ }^{52}$ Por su parte, en el municipio de Lanús el Servicio Local había incorporado un profesional en la Comisaría de la Mujer a modo de enlace permanente para las situaciones donde niños/as estuviesen involucrados/as. ${ }^{53}$

\subsection{Una mirada territorial a las políticas de infancia y adolescencia}

En el campo de las políticas sociales y en contraste con los años noventa, cuando la aprobación de la Convención por los Derechos del Niño se dio en un contexto de recesión 
y ajuste fiscal, los años de implementación de la ley en el período analizado (2007-2015) muestran una ampliación de las políticas de seguridad social, ${ }^{54}$ donde con relación a la niñez y la adolescencia destaca por su masividad la Asignación Universal de Protección Social por Hijo (AUH). En contraste, aun cuando hubo programas destacados en algunas áreas sectoriales (en Salud el Nacer/Sumar y el Remediar, y en Educación el Conectar Igualdad) no se generó un proceso similar en los servicios de proximidad ni, particularmente, en programas socioeducativos y/o de cuidado (en el caso de la primera infancia) de alcance masivo en el territorio que acompañaran ese proceso de expansión de derechos. El déficit de vacantes en servicios educativos y de cuidado para la primera infancia es una constante en los barrios más postergados. Los espacios institucionales y/o proyectos para adolescentes son escasos en los barrios y en la mayoría de los casos con fuerte presencia, en cambio, de organizaciones comunitarias y no gubernamentales.

La promoción de derechos en territorios signados por procesos de segregación socioeconómica de larga data requiere la presencia de políticas sociales universales (educación y salud) más una oferta amplia, pertinente y de calidad de propuestas socioeducativas que hagan puente con la escolaridad formal y -eventualmente- tengan la capacidad de constituirse en redes de sostén ante situaciones críticas de la crianza y/o vulneración de derechos.

Por tanto, se requiere una nueva arquitectura cuyo eje prioritario debiese estar en la ampliación de una oferta socioeducativa con mayor foco en dos sectores críticos: ${ }^{55} \mathrm{I}$ ) primera infancia,${ }^{56}$ sector con escasa cobertura de servicios educativos y de cuidado que resultan claves y estratégicos en términos de desarrollo y de incidencia en múltiples factores que generan desigualdades, tanto en las trayectorias biográficas como en la desigualdad de género persistente respecto a la organización doméstico familiar, e indirectamente en la situación de pobreza ${ }^{57}$ II) el otro sector crítico y muchas veces escasamente visibilizado, es el de las políticas dirigidas a la adolescencia, también con poca oferta programática socioeducativa (incluso con déficit de cobertura en las escuelas secundarias públicas) y clave para construir dinámicas sociales de cohesión e inclusión social en los territorios.

La expansión de una oferta programática socioeducativa y de cuidado es un requisito para construir efectivamente un sistema que logre plasmar derechos de manera más igualitaria en la niñez y la adolescencia. Este "piso" de derechos es indispensable para construir articulación y acciones conjuntas entre las líneas de promoción a escala territorial y las intervenciones de restitución de derechos a través del trabajo en red que involucre a los servicios de educación y salud y demás actores territoriales. ${ }^{58}$ En ese terreno hay mucho camino por recorrer para consolidar un marco de trabajo común que opere bajo una lógica de corresponsabilidad, donde los diferentes actores sectoriales y territoriales se involucren activamente no sólo para acordar criterios y estrategias de intervención, sino también para constituir 'autopistas' en el acceso a recursos. Este proceso debiese ir acompañado por un fuerte aval político del más alto nivel de gobierno, 
la construcción de acuerdos marco entre las áreas sectoriales, conjuntamente con la jerarquización de los operadores y equipos técnicos-profesionales.

Por su parte, específicamente en lo que hace a las intervenciones de restitución de derechos, además de la compleja tarea de coordinar redes territoriales con capacidad de constituirse como redes de sostén ante situaciones críticas, la propuesta de repensar la arquitectura implica una coordinación fuerte -o incluso una integración según lo ameriten las situaciones- entre los equipos de niñez y los equipos especialistas en género para la atención de situaciones de violencias. También se debería repensar la articulación entre las áreas de niñez y las abocadas el consumo problemático de sustancias tanto desde lo asistencial como lo promocional teniendo en cuenta su incidencia en los adolescentes, el déficit de los actuales servicios y considerando, además, que esta temática involucra dinámicas territoriales que en buena medida exceden los ámbitos de competencia de dichas áreas (donde con frecuencia aparecen involucradas las fuerzas de seguridad y algunos referentes o grupos organizados dedicados al narcotráfico).

Tampoco se trata de caer en facilismos normativos que postulan un deber ser sin reconocer la complejidad intrínseca a las problemáticas que afrontan estas áreas de niñez y adolescencia. En términos de agenda de gobierno (establecer prioridades en términos recursos y marcar el rumbo de las políticas) esto plantea una tensión inherente porque, de hecho, estas áreas no pueden desentenderse de la atención de situaciones de vulneraciones que mayoritariamente plantean urgencias y/o emergencias -por ende, con todas las implicancias de actuar con premura y coordinar equipos profesionales expuestos a contener e intervenir en situaciones críticas-. Ante estas situaciones, la rutinización o burocratización (en un sentido no peyorativo que hace referencia a la estandarización de procedimientos que en otras organizaciones facilita y hace predecibles las intervenciones) se plantea como un riesgo de desconexión con respecto a los sujetos y los vínculos en juego. El esquema de la "mera derivación” sería una expresión cabal de esto, con intervenciones parciales que inciden en la fragmentación de la vida de los sujetos y no logran cobijar y contener a quienes atraviesan situaciones críticas de padecimiento. Mientras que, en contrapunto, la corresponsabilidad plantea un abordaje en forma conjunta con las otras áreas a partir del reconocimiento de cada sujeto, de una escucha analítica que permita recomponer vínculos (cuando es posible) y construir lazo social para restituir derechos. Ahora bien, las articulaciones requieren, además de la voluntad de los actores involucrados en esas instancias, de aval político y disponibilidad de recursos.

No deseamos cerrar este artículo sin hacer dos menciones: una en términos de reconocimiento hacia quienes están ahí y ponen el cuerpo en los territorios -tanto en la diversidad de programas socioeducativos y centros de cuidado como en los servicios locales-; la otra refiere al actual contexto político y las incertidumbres que plantea. 
El lugar del compromiso y la reivindicación no elude la autocrítica siempre necesaria pero esto no implica invalidar los esfuerzos sostenidos que se llevan a cabo en las diferentes jurisdicciones y territorios. Son numerosas y variadas las experiencias de abordajes socioeducativos y de cuidado que, como denominador común, transforman en acto el postulado de reconocer a la niñez y a la adolescencia como sujetos de derechos (generan un reposicionamiento de los propios sujetos, construyen vínculos significativos con los referentes adultos y con los grupos de pares, sostienen una presencia continua a través de ofertas pertinentes y de calidad, entre otras características distintivas de estos abordajes). También hay experiencias relevantes de atención a la emergencia a través de servicios y de programas de acompañamientos donde se torna clave la escucha, la confianza, la capacidad de decir y/o hacer algo que resuene y deje alguna marca de incidencia subjetiva. Para cualquier de estos dispositivos la cuestión clave pasa por los llamados recursos humanos: operadores, educadores, promotores, acompañantes, talleristas, equipo técnico y profesionales, son en definitiva quienes dirimen el alcance y el sentido de una política de estas características. Sin embargo, en términos relativos con las áreas sectoriales tradicionales -como salud y educación pero más aún si se contrasta con el sistema judicial- el personal de estos programas de atención de vulneraciones, de cuidado y socioeducativos todavía requiere reconocimiento y jerarquización en la mayoría de las municipalidades del conurbano.

Finalmente, una mención al contexto actual. Una gran incógnita se genera ante el nuevo escenario político y el devenir de las políticas sociales bajo un modelo económico de orientación neoliberal. La construcción y consolidación de un sistema de protección y promoción de derechos para la niñez y la adolescencia sólo es posible en una sociedad y una economía que genere trabajo digno para los adultos, políticas sociales universales y procesos de urbanización inclusivos con acceso a bienes culturales ${ }^{59}$ La primacía de una lógica de mercado global plantea límites ostensibles para la construcción de mayor igualdad y de manera recurrente -en distintas geografias de la región a lo largo de la historia reciente- ${ }^{60}$ suele traer el correlato de la mano dura como política de estado para los adolescentes y jóvenes de las periferias, ${ }^{61}$ donde consolida una experiencia juvenil acosada cotidianamente por las fuerzas de seguridad. ${ }^{62}$

En este escenario no sería extraño que se tienda a profundizar el perfil asistencialista en desmedro de pensar una lógica de lo común y universal que construya igualdad en el acceso a derechos. Aun así, con las limitaciones de esta compleja dinámica política y societal, algunos niveles de gobierno (dependiendo del proyecto político que promueven) podrán generar mayores márgenes de acción y en otras instancias, claramente, habrá que apelar a las obligaciones inalienables del Estado y a la capacidad de todos los actores involucrados en la construcción de un sistema de promoción y protección de derechos (tanto estatales como organizaciones sociales y aun del ámbito académico) para sostener lo realizado, interpelar al poder político en la orientación de esta nueva institucionalidad y pugnar por condiciones efectivamente más igualitarias para toda la niñez y la adolescencia. 


\begin{abstract}
${ }^{1}$ Agradezco los comentarios de quienes realizaron la evaluación anónima de este artículo y la lectura crítica de Gilda Manco. ${ }^{2}$ El Conurbano Bonaerense refiere a los 24 municipios que se conformaron en la circunvalación periférica de la Ciudad de Buenos Aires. Según los datos arrojados por el Censo del 2010 habitan esta región una población total de 9.910.282 habitantes, con un incremento de casi el 13\% respecto al censo anterior del año del 2001. Se trata de un área urbana muy amplia espacialmente y heterogénea en cuanto a perfiles y dinámicas socioeconómicas que, como región, carece de una institucionalidad formal en términos de gobernabilidad. En un plano sociocultural, su mención remite con frecuencia a una construcción de sentido en la que 'el conurbano' aparece como un territorio sin ley que se define en contraste con la ciudad civilizada (los medios de comunicación suelen fomentar esta dicotomía que se retroalimenta en estereotipos históricos, étnicos y de clase). ${ }^{3}$ El proyecto "La construcción de una nueva institucionalidad pública a nivel local: las áreas de niñez y adolescencia en el conurbano bonaerense" estuvo radicado en el Área de Política Social del Instituto del Conurbano de la Universidad Nacional de General Sarmiento. Se propuso analizar la construcción de una nueva institucionalidad pública y las tensiones que se presentan al momento de su implementación.

${ }^{4}$ Se realizaron entrevistas a actores clave de los sistemas locales de las municipalidades de La Matanza, Quilmes, Lanús, Morón, y San Martín. Los dos primeros fueron seleccionados para estudios de caso en función de características propias de cada municipio que ofrecía más variantes en el proceso de implementación y ello aportaba mayor densidad empírica para los objetivos de la investigación.

${ }^{5}$ Para la elaboración de los estudios de caso y la contextualización de los municipios del conurbano bonaerense se utilizaron las tesis de licenciatura de García, Conrado (2013), de maestría de Agustín Barna (2016) y de doctorado Magistris, Gabriela (2016) así como el relevamiento realizado por UNICEF, Secretaría de Niñez y Adolescencia y Grupo Pharos (2016) más el Informe de Gestión del REUNA 2010 y el informe de
\end{abstract} la Secretaría de Desarrollo Social Quilmes (2015).

${ }^{6}$ La ya clásica publicación de Platt (1982) puso al descubierto los efectos selectivos sobre un sector de la infancia al que ese movimiento reformista postulaba rescatar.

${ }^{7}$ Frigerio (2008) señala que, en contraste al árbol genealógico de una familia, la inscripción de estas instituciones genera un no lugar, una filiación trunca o que filia a un limbo que no perpetúa relaciones vinculares. ${ }^{8}$ Se trata de una desigualdad categorial en los términos que plantea Tilly (2000). Siguiendo la línea conceptual propuesta por este autor y su preocupación en torno a los mecanismos sociales de construcción de desigualdad persistente (ver específicamente el capítulo 3), en este caso en particular, se instituye a partir de organizaciones que generan el binomio niñez/minoridad y que, en un plano social más amplio converge con las categorías abarcadoras propias de una sociedad de clases. De este modo, la operatoria de estas instituciones resultaba altamente selectiva hacia la población infantil de los sectores populares.

${ }^{9}$ La Convención sobre los Derechos del Niño fue aprobada por la Asamblea General de las Naciones Unidas el 20 de noviembre de 1989; en Argentina primero fue ratificada y posteriormente obtuvo rango constitucional con la reforma del año 1995.

${ }^{10} \mathrm{El}$ concepto de reenmarque refiere a “...una manera de seleccionar, organizar, interpretar y dar sentido a una realidad compleja en tal forma que nos ofrezca puntos de guía para conocer, analizar, convencer y actuar. Un marco es una perspectiva desde la cual se puede dar sentido a una situación amorfa, problemática y mal definida, y actuar en consecuencia" (Rein y Schon 1999: 329).

${ }^{11}$ Esta breve referencia contextual tiene la intención de no restringir el cambio de modelo a los efectos de la Convención Internacional sobre Derechos del Niño (para una reseña del proceso de gestación de la convención en el plano regional e internacional ver Pilotti 2001). Si bien esta normativa y Unicef tuvieron un papel protagónico en la construcción de nuevos discursos y consensos entre los saberes expertos y los actores relevantes, eso no explica toda la dinámica que se gestaba en las propias áreas estatales, en el ámbito de las ONGs y de las organizaciones comunitarias. En el plano regional, la reforma del estatuto del Niño en Brasil (en 1988) es demostrativa de un giro conceptual con amplia movilización de organizaciones de base que antecede a la propia Convención. Este proceso del vecino país fue seguido con mucha atención en Argentina, particularmente por las áreas de niñez y adolescencia que estaban generando una nueva oferta programática. ${ }^{12}$ Las comillas refieren a un uso laxo del término gestión asociada, se trató de un proceso paulatino que con el tiempo fue cristalizando institucionalmente (esto es con normativa, acuerdos-marco, roles definidos, modalidad de financiamiento, etc.) pero que inicialmente se sustentaba más en relaciones de interpersonales. ${ }^{13}$ Los primeros programas que se autoproclamaban como alternativos se generaron en la segunda mitad de la década de 1980 en la Ciudad de Buenos Aires, por entonces Municipalidad -el programa "Cuidemos Nuestros Niños"- y en el nivel nacional a través del programa de operadores de calle -dependiente del Consejo del Menor-. La otra característica del período fue la expansión de subsidios y becas a los pequeños hogares (de "puertas abiertas") que se planteaban como opción cuando la revinculación familiar no era posible y se quería evitar la internación en macro-institutos privativos de la libertad.

${ }^{14}$ En un balance de aquellos años Gomes da Costa (1995), impulsor de la nueva corriente en Brasil, señalaba la 
necesidad de consolidar estas políticas ya no sólo como alternativas sino más bien como alterativas, apuntando a la necesidad de desmontar el patronato y no de construir programas como estructuras paralelas.

${ }^{15}$ Esta modalidad de abordaje que conjuga una labor educativa (no escolar) y lúdica más un trabajo territorial en red cuenta con variadas experiencias en la Ciudad Autónoma de Buenos Aires (CABA) y en el conurbano, desarrolladas por organizaciones comunitarias y por programas de áreas estatales (aunque la escala en buena parte de los municipios y en algunos barrios de la CABA continúa siendo muy acotada). Para una experiencia valiosa al respecto ver Soler y Monzani (2006).

${ }^{16}$ Chubut fue la primera en el año 1998.Y el Congreso Federal de ese mismo año impulsado por Unicef es emblemático en cuanto a la confrontación entre actores estatales impulsores de un cambio de modelo bajo el amparo de la CIDN y quienes aun defendían la lógica tutelar (el Consejo del Menor y buena parte de los actores del poder judicial). ${ }^{17}$ Estrictamente la aprobación de la ley es unos meses anterior a la ley nacional y contaba con un antecedente de reforma -la ley provincial 12.607- que intentó terminar con el patronato en el año 2000 pero que fue derogada (primero por un recurso de inconstitucionalidad presentado por la Procuración General y luego, una vez que la Corte Suprema había desestimado este recurso, por la propia Legislatura Provincial).

${ }^{18}$ Juan Pablo Cafiero, Ministro de Desarrollo Social de la provincia de Buenos Aires, al presentar la ley, en declaración al diario Página12 (14/02/05), apud Guemureman y Azcárate (2005:1).

${ }^{19}$ En el momento mismo de promulgación de la ley, el ejecutivo realizó varias observaciones respecto a la superposición de funciones con el registro de Personas Jurídicas, con el Ministerio de Justicia, así como con respecto a las competencias de los municipios y a la asignación de funciones del asesor de incapaces (Guemureman y Azcárate, 2005). La medida cautelar interpuesta por la Procuradora General de la Provincia al día siguiente de su entrada en vigencia, obligó al ejecutivo a una detallada reglamentación para poner en funcionamiento los nuevos organismos mencionados en la ley con recursos humanos y partidas presupuestarias. Como mencionan estas autoras en el artículo citado, además de la disputa coyuntural entre líneas internas en el peronismo provincial, los cuestionamientos ponen de manifiesto el conflicto entre el poder (o mejor, la corporación) judicial y los órganos político-administrativos. ${ }^{20} \mathrm{El}$ art. 23 de la ley 13.298 crea un Comité interministerial presidido por el Ministerio de Desarrollo Humano. La Comisión Interministerial para la Promoción y Protección de los Derechos del Niño se constituye con los titulares de los ministerios y secretarías enunciados en el artículo 23 de la ley 13298: Ministerios de Desarrollo Humano, Gobierno, Justicia, Seguridad, Producción, Salud, Trabajo, Dirección General de Cultura y Educación, así como las Secretarías de Derechos Humanos y de Deportes y Turismo.

${ }^{21}$ En materia de producción y gestión de información el Ministerio de Desarrollo Social provincial desarrolló (desde el año 2010) el Registro Estadístico Unificado de Niñez y Adolescencia (REUNA) que en una primera etapa concentraba información proveniente de los Servicios Zonales (es decir las instancias desconcentradas dependientes del propio ministerio y a través de las cuales se tramitaban las medidas excepcionales de protección) y posteriormente fue incorporando la carga a nivel de los servicios locales (aunque a la fecha no son la totalidad de los servicios locales). Tal como se menciona en el Informe de Gestión de junio de 2010 se trata de un sistema de información inédito en tanto las antiguas áreas de minoridad carecían de una base unificada. Las estadísticas de los registros -y esto coincide con las bases de los servicios locales analizadas- indican que la mayoría de las situaciones se originan en casos de violencias y abusos. La información del REUNA para los municipios del conurbano correspondiente al año 2014 puede consultarse en el Observatorio del Conurbano ICO-UNGS. http://observatorioconurbano.ungs.edu.ar/?page_id=8249

22 Otros organismos novedosos que también proponía la ley fueron la creación de consejos locales con participación de organizaciones de la sociedad civil y universidades, así como la creación de un observatorio social (también con participación de organizaciones de sociedad civil, colegios profesionales y universidades). ${ }^{23}$ Para un desarrollo más exhaustivo de los cambios en la orgánica ministerial ver Magistris y Litichever (2013). ${ }^{24} \mathrm{~A}$ tal punto que en los años recientes desde la Secretaría de Niñez se creó una nueva instancia de coordinación, ya no entre áreas del gobierno provincial sino un consejo con participación de los municipios.

${ }^{25}$ Hacia fines de 2015, 123 municipalidades de las 135 de la Provincia habían firmado la adhesión (Roffler, 2016). 26 “Nosotros dijimos que sí había que firmar porque había que cambiar el paradigma. En el municipio había mucho lobby de jueces tutelaristas, uno de ellos ya había pedido entrevista con el intendente" (entrevista con Secretaria de Desarrollo Social de una Municipalidad del sur del conurbano). "Fue costoso firmar el convenio, convencer al intendente (sobre) un paquete sin demasiados recursos porque no vino con fondos extras... más adelante, en el proceso de implementación, en algún momento me lo recriminaron..." (ex jefe de gabinete del municipio de La Matanza, reconocido como impulsor del sistema local).

${ }^{27}$ Por ejemplo medidas de abrigo (que implican un avance sobre la patria potestad de los padres).

${ }^{28}$ Mediante la resolución 166 del año 2007 el Ministerio dio de baja a las delegaciones departamentales de Minoridad y en su reemplazo creó los Servicios Zonales de Promoción y Protección de Derechos del Niño. Inicialmente dichos Servicios Zonales se crearon en correspondencia con las regiones educativas y posteriormente se readecuaron en relación a los departamentos judiciales (Magistris y Litichever, op. cit.) 
${ }^{29}$ Este elemento se presenta como una constante en cada uno de los servicios locales indagados, aun en aquellos que daban cuenta de una buena relación con el Servicio Zonal. El conflicto no se plantea sólo por conseguir la vacante sino que intervienen factores críticos a cada estrategia de intervención, tales como el tipo de institución (existe mucha heterogeneidad en tipo y calidad del servicio), los tiempos en que se otorga la vacante (en muchos casos se requiere con urgencia) o la distancia respecto del lugar de residencia (lo que puede implicar no sólo salir del ámbito familiar sino, por ejemplo, dejar de concurrir a la escuela a la que iba, pérdida de amistades, etc.). ${ }^{30}$ La ley y su decreto regulatorio establecen que el equipo de cada local debe estar constituido por un equipo técnico integrado como mínimo por un psicólogo, un abogado, un trabajador social y un médico. Art. 20 ley 13.298. ${ }^{31} \mathrm{El}$ art. 30 de la ley menciona programas: a) de identificación, b) de defensa de derechos, c) de formación y capacitación, d) recreativos y culturales y e) de becas y subsidios.

32 (...) el sistema local de protección y promoción de derechos en la Matanza es mucho más que el Servicio Local, abarca una cantidad de oferta programática (entrevista a Director de Niñez y Adolescencia - La Matanza). Las Municipalidades de La Matanza, Morón y Quilmes muestran en el período analizado una importante expansión de la oferta programática, en algunos casos con financiamiento propio y/o del nivel nacional (la mención de estos casos no es excluyente con respecto a lo realizado en otros municipios). No obstante, vale destacar que la escala de incidencia de esa nueva oferta estuvo lejos de cubrir las necesidades de esos territorios. ${ }^{33}$ La Secretaría de Desarrollo Social de la Municipalidad de Quilmes en el año 2007 elaboró un diseño que proponía una primera instancia de construcción territorial con creación de oferta propia y, sobre todo, a través de una gestión asociada y/o del fortalecimiento de las organizaciones territoriales que trabajan con la niñez y adolescencia en los barrios. Posteriormente -una vez conformada la red de trabajo en una variada oferta programática en territorio- se iniciaría el trabajo de atención por casos. En los hechos, si bien no se constituyó formalmente como servicio local, la alta recepción de situaciones urgentes de vulneración de derechos en la infancia llevó a la creación de un equipo de restitución de derechos -lo que a su vez implicó un trabajo muy exigente para formar y consolidar ese equipo-. (entrevistas a la ex-secretaria de Desarrollo Social y a la ex-subsecretaria de Infancia, Municipalidad de Quilmes).

${ }^{34}$ Se refiere a Ituzaingó y Hurlingham.

${ }^{35}$ Además de La Matanza y Quilmes (seleccionadas para estudio de caso) también se realizaron entrevistas en Lanús, Morón y San Martín.

${ }^{36}$ Desde el nivel provincial se reconocen las dificultades de coordinar a las municipalidades del conurbano, donde la autonomía cobra mayor relevancia: "trabajamos mucho en capacitaciones en el interior pero en el conurbano, por ejemplo, las capacitaciones no entraban, era muy dificil... aun reconociendo que hay municipios con políticas de niñez interesantes" (entrevista, a ex Subsecretario de Niñez y Adolescencia de la Provincia de Buenos Aires).

${ }^{37}$ Reconoce tres modalidades: 1) Jardines Maternales Comunitarios: (Para niños y niñas de 45 días a 5 años). Se realizan actividades de estimulación temprana a cargo de "mamás cuidadoras", promotoras socio-comunitarias capacitadas y/o personal docente. 2) Casas del Niño: (Para niños y niñas de 6 a 14 años). Funcionan en contraturno escolar. Brindan apoyo y acompañamiento escolar junto a distintas actividades recreativas. 3) Centros Juveniles: (Para adolescentes y jóvenes de 14 a 18 años). Funcionan diariamente en contraturno escolar. Sus actividades apuntan a la capacitación y estimulación para la inserción laboral, educacional y ocupacional de los jóvenes. https://www.gba.gob.ar/es/desarrollosocial/asistencia/udi

${ }^{38}$ El programa Envión destinado a adolescentes y jóvenes de 12 a 21 años en situación de vulnerabilidad social tampoco presenta un alcance significativo en términos de cobertura y en alguno de los municipios relevados desde el gobierno local deben adicionar un porcentaje considerable del salario debido a las bajas remuneraciones con respecto al plantel municipal.

${ }^{39}$ De manera recurrente los testimonios recogidos en el trabajo de campo refieren a un déficit tanto en cantidad como en la calidad de los hogares dependientes del gobierno provincial.

${ }^{40}$ Por ejemplo, durante todo el período analizado en la Provincia de Buenos Aires se pagaba menos que en la CABA por el mismo tipo de servicio. Este punto también da cuenta de un área de vacancia a nivel nacional para establecer pautas relativamente comunes según la modalidad del servicio.

${ }^{41} \mathrm{El}$ déficit de regulación y el bajo financiamiento generan condiciones propicias para la continuidad de un escenario muy heterogéneo en términos de calidad del servicio que brindan estas instituciones y genera un vacío que puede encubrir situaciones muy irregulares.

${ }^{42}$ El programa Propiciar en la municipalidad de La Matanza es un ejemplo de este tipo de intervenciones, en este caso para adolescentes no punibles con algún hecho de conflicto con la ley penal (para un análisis de este Programa ver Moro y Orizaola 2017). Más recientemente (2014) en el mismo municipio se puso en marcha un programa de acompañamiento a los procesos de adopción (Programa Ahijar). Los “educadores de ciudadanía” en Quilmes también presentaban un formato de acompañamiento -en este caso a familias- ante derechos vulnerados y desarrollaban una acción centrada en la articulación con otras instituciones, servicios y/u organizaciones barriales -este programa se discontinuó con el cambio de gestión en 2015- (entrevista a Coordinadora de proyectos territoriales - Quilmes).

43 “Sustituir la práctica de la 'derivación' de casos entre instituciones por la construcción de relaciones de 
corresponsabilidad e interdependencia entre las mismas con el objeto de promover, proteger y restituir derechos en forma integral..." (art. 21.3.4 Dto. 300/05).

${ }^{44}$ Este punto también encuentra coincidencia con el relevamiento del año 2014 (ver SNyA-UNICEF-Pharo, 2015:26).

${ }^{45}$ Entrevista a trabajadora social del Servicio Local de San Martín.

${ }^{46}$ Entrevista al Director de Niñez y Adolescencia de La Matanza.

${ }^{47}$ En Quilmes se desarrollaron algunas iniciativas para incorporar en los protocolos de intervención y en el sistema de registro local "la voz del niño/a" (entrevista a ex subsecretaria de Infancia).

48 "Lo que había en Quilmes era mucho trabajo territorial de organizaciones comunitarias y ONGs, con financiamiento, algo de la Provincia, de agencias del exterior y de la iglesia (Caritas). La pregunta entonces era qué hacer? competir?... y una primera definición fue apoyar a las organizaciones" (ex secretaria de Desarrollo Social - Quilmes). En contrapunto, el vínculo entre los gobiernos locales y algunas organizaciones puede tornarse conflictivo. Al respecto, un caso bastante extremo fue el hostigamiento que debieron soportar los referentes de los Centros Comunitarios Angelelli por parte del intendente de Florencio Varela. Organizaciones de peso como Caritas y el CELS hicieron público su respaldo a la dicha organización ante la escalada del conflicto (la participación de dicha organización en la organización de asentamientos y tomas de tierra fue parte fundamental del conflicto). http://www.lanacion.com. ar/1674079-florencio-varela-denuncian-que-hay-narcos-detras-de-las-tomas-de-tierras

${ }^{49} \mathrm{La}$ universalidad refiere a la accesibilidad al derecho, si bien requiere de una cobertura universal, la misma no opera automáticamente como sinónimo de universalidad. De hecho la heterogeneidad en cuanto a la calidad de los servicios plantea serios problemas de segmentación que, como señala Filgueira (2014), dan cuenta de un universalismo (todavía) estratificado en los países del cono sur.

${ }^{50}$ Desde una perspectiva feminista la autora critica el enfoque técnico-burocrático en el tratamiento de la violencia doméstica hacia las mujeres, a través de diagnósticos psicosociales que recortan exclusivamente por la singularidad de cada familia y de los vínculos de pareja. Con dos efectos, una despolitización de la cuestión al diluir y/o relegar la perspectiva más amplia y crítica respecto de una sociedad patriarcal y, a la vez, con una interpelación a las mujeres casi exclusivamente en calidad de víctimas (mientras que el feminismo las reconoce e interpelaba como potencialmente militantes de un movimiento de emancipación e igualdad).

${ }^{51}$ Esto se verifica tanto en los registros del REUNA como en las bases de datos de los propios servicios locales.

${ }^{52}$ La referencia es a la UGC de Castelar Sur donde llaman a este dispositivo "ventanilla única" y proponían evitar una reiteración del testimonio de las víctimas, por lo que profesionales de ambos equipos (género e infancia) realizaban la primera entrevista y luego definían conjuntamente la/s estrategia/s de intervención. (entrevista a subdirector de la UGC).

${ }^{53}$ Aun así, en este caso no había articulación entre el Servicio Local y la Dirección de Género de la misma Municipalidad (entrevista a trabajadora social del Servicio Local).

${ }^{54} \mathrm{La}$ moratoria previsional permitió una cobertura casi universal de jubilaciones y pensiones. También aumentó significativamente la cobertura de pensiones para personas con discapacidad.

${ }^{55}$ Se retoman aquí algunas ideas presentadas en Monzani, Moro y Soler (2012).

${ }^{56} \mathrm{Ha}$ habido avances sobre todo en términos de agenda, donde la primera infancia y puntualmente la ampliación de los centros educativos y de cuidado son explícitamente presentados como propuestas de gobierno. En este sentido, esta coyuntura ofrece una oportunidad. Sin embargo, esta retórica aun no se plasma en una expansión significativa de estos servicios. A nivel local en el conurbano bonaerense se destaca la iniciativa de la Municipalidad de San Miguel que desde hace algunos años creó una coordinación de primera infancia (bajo una concepción de carácter transversal). ${ }^{57} \mathrm{Al}$ fomentar la inserción laboral de quienes están a cargo del cuidado, que son mayoritariamente mujeres. La generación de un nuevo ingreso para el grupo familiar suele ser uno de los factores de mayor incidencia para salir de lo que se conceptualiza como situación o línea de pobreza.

${ }_{58}$ En torno a la concepción de "piso de derechos" ver OIT (2011).

${ }^{59}$ Excede los alcances de este artículo pero es ostensible que los niveles de segregación espacial generan dinámicas sociales que condicionan fuertemente la incidencia de las políticas de promoción y acceso a derechos. ${ }^{60}$ Para una referencia a las políticas de mano dura en Centroamérica, ver los capítulos de la segunda parte de Moro (2006) particularmente el de Cruz y Carranza (2006) para el caso de El Salvador y el de Rocha (2006) para Nicaragua. ${ }^{61} \mathrm{El}$ proyecto oficial para bajar la edad de inimputabilidad es un claro ejemplo al respecto y debe ser ponderado en este contexto. La Coordinadora Contra la Represión Policial e Institucional (Correpi) viene denunciando cifras record de violencia institucional en casos llamados de "gatillo fácil" https://www.clarin.com/ politica/Denuncian-Macri-absoluto-violencia-institucional_0_Hy7q--yEx.html.

${ }^{62}$ Esta experiencia "no es, por cierto, exclusivamente intelectual. Se inscribe en los cuerpos de los adolescentes de dos maneras distintas y complementarias. Por un lado, los jóvenes comprenden lo que encarnan ante los ojos de la sociedad ('miren lo que son' se les dice). Por otro, incorporan esa representación que se les da de ellos mismos ('¡iconviértanse en lo que son!'les ordenan). Esta puesta en juego del cuerpo -encarnación e incorporación- escapa en parte a la conciencia.Se la siente más que se la analiza. Se traduce en las emociones... en ese miedo ante los policías..." (Fassin 2016:34). 


\section{Referencias bibliográficas}

Barna,Agustín (2013) Institucionalización de los derechos del niño en contextos de desigualdad social,Tesis de Maestría en Diseño y Gestión de Programas Sociales, FLACSO-Argentina.

Barna, Agustín (2014) “Clasificaciones y estimaciones en la gestión de la infancia “con derechos vulnerados". Prácticas cotidianas de intervención en un dispositivo estatal del conurbano bonaerense" Revista Antropolítica, 36:113-148.

Barzelay, Michael y Cortázar, Juan Carlos (2004) Una guía práctica para la elaboración de estudios de caso sobre buenas prácticas en gerencia social, Instituto Interamericano para el Desarrollo Social (INDES) Banco Interamericano de Desarrollo, Washington D.C.

Beloff, Mary (1999) "Modelo de la protección integral de los derechos del niño y de la situación irregular: un modelo para armar y otro para desarmar", en Justicia y Derechos del Niño, UNICEF-Ministerio de Justicia, Buenos Aires.

Bourdieu, Pierre y Wacquant, Loïc (1995) Respuestas por una Antropología Reflexiva, Grijalbo México DF.

Colángelo, María (2008) “La construcción médica del niño y del cuerpo infantil: los discursos y las prácticas de pediatría entre 1890 y 1930”, ponencia presentada en las Jornadas de Historia de la Infancia en Argentina: 1880-1960, UNGS-UdeSA.

Costa, Mara y Carigliano, Rafael (2000) “Las infancias de la minoridad. Una mirada histórica desde las políticas públicas”, en Duschatzky, Silvia (comp.) Tutelados y asistidos. Programas sociales, políticas públicas y subjetividad, Ed. Paidós, Buenos Aires pág. 69-119.

Cruz, José y Carranza, Marlon (2006) "Pandillas y políticas públicas: el caso de El Salvador" en Moro, Javier (ed.) Juventudes, violencia y exclusión: desafíos para las políticas públicas, INDES-INAP-Magna Terra Ed. Guatemala, pág. 133-176.

Cunill-Grau, Nuria; Repetto, Fabián y Carla Bronzo (2015) “Coordinación intersectorial pro integralidad de las instituciones de protección social”. En Cecchini, Simone; Fernando Filgueira; Rodrigo Martínez; y Cecilia Rossel (eds.)Instrumentos de Protección Social. Santiago de Chile: CEPAL, pág. 407-444.

Fassin, Didier (2016) La fuerza del orden. Una etnografía del accionar policial en las periferias urbanas, Ed. Siglo XXI, Buenos Aires. 
Filgueira, Fernando (2014) Hacia un modelo de protección social universal en América Latina. Santiago de Chile: CEPAL, Serie Políticas Sociales.

Fraser, Nancy (2001) "La lucha por las necesidades: esbozo de una teoría crítica socialista-feminista del capitalismo tardío", en Lamas, Marta (comp.); Ciudadanía y feminismo. México D.F.: Ed. UNIFEM / IFE / Debate Feminista, págs.115-155.

Frigerio, Graciela (2008) La división de las infancias. Buenos Aires: Ediciones del Estante.

García Rodríguez, Conrado (2013) La dimensión territorial de las políticas de infancia: La Implementación de la Ley Provincial 13298 de Protección y Promoción Integral de los Derechos del Niño en contextos de desigualdad social. El caso del Municipio de La Matanza. Tesis de Licenciatura de la Carrera de Política Social, Universidad Nacional de General Sarmiento.

Goffman, Erving (1972) Internados Ensayos sobre la situación social de los enfermos mentales. Buenos Aires: Amorrortu.

Goffman, Erving (1987) Estigma. Buenos Aires: Amorrortu.

Gomes da Costa, Antonio (1995) Pedagogía de la presencia. Buenos Aires: Losada.

Larrandart, Lucila (1992) "Desarrollo de los tribunales de menores en Argentina: 1920-1983”, en García Méndez, E. y Carranza, E. (comp..) Del revés al derecho. La condición jurídica de la infancia en América Latina. Buenos Aires: Galerna, págs.21-113.

Magistris, Gabriela y Litichever, Cecilia (2013) “Transformaciones institucionales en el campo de las políticas sociales para la niñez y adolescencia”, en Llobet, Valeria (coord.) Sentidos de la exclusión social. Beneficiarios, necesidades y prácticas en políticas sociales para la inclusión de niños y jóvenes.Buenos Aires: Ed. Biblios, págs.51-72.

Magistris, Gabriela (2016) “El gobierno de la infancia en la era de los derechos.Prácticas locales de "protección y restitución de derechos de Niños, Niñas y Adolescentes". Tesis de doctorado, Facultad de Ciencias Sociales Universidad de Buenos Aires.

Monazani, María Ana; Moro, Javier y Soler, Graciela (2012) Por una nueva 'arquitectura' de las políticas sociales territoriales para la niñez y la adolescencia. Ponencia presentada en el V Congreso Mundial por los derechos de la infancia y la adolescencia. San Juan San JuanArgentina. Descargable de https://es.ecribd.com/doc/114223067/Lobro-de-Ponencias-VCongreso-Mundial-Por-Los-Derechos-de-La-Infancia-y-Adolescenciaq-Argentina-2012 
Moro, Javier (1997) “La definición del problema en la elaboración de las políticas: los 'menores' en la agenda de gobierno”. Perfiles Latinoamericanos vol. 6 N¹0, pág.139-162.

Moro, Javier y Orizaola, Guillermo (2017) “Adolescentes con episodios conflictivos con la ley penal: restituir derechos y construir ciudadanía. Reflexiones a partir del Programa Propiciar de La Matanza”. Revista Perspectivas de Políticas Públicas vol. 6 No12:305-331.

Moro, Javier (2006) Juventudes, violencia y exclusión: desafíos para las políticas públicas. Ciudad de Guatemala: INDES-INAP-Magna Terra.

OIT, Organización Internacional del Trabajo (2011) Piso de Protección Social para una globalización equitativa e inclusiva. Informe del Grupo consultivo sobre el Piso de Protección Social. Ginebra: OIT.

Pilotti, Francisco (2001) Globalización y Convención sobre los Derechos del Niño: El contexto del texto. Santiago de Chile: CEPAL, División de Desarrollo Social, Serie Políticas Sociales № 48.

Platt, Anthony (1982) Los "salvadores del niño" o la invención de la delincuencia, México D.F. Siglo XXI.

Rein, Martin y Schon, Donald (1999) “Un discurso de políticas que refleja su marco”, en Wagner, P., Weiss, C., Wittrock, B. y Wollman, H., Ciencias sociales y estado moderno Ex-periencias nacionales e incidencias teóricas. México D.F: Fondo de Cultura Económica, págs.327-357.

Rocha, José Luis (2006) “Violencia y políticas públicas hacia los jóvenes: las pandillas en Nicaragua” en Moro, Javier (ed.) op.cit., págs.177-210.

Roffler, Érika (2016) La institucionalidad del Sistema de Promoción y Protección de Derechos de Niñas Niños y Adolescentes en la provincia de Buenos Aires: avances y desafíos pendientes. Ponencia presentada en $8^{\circ}$ Congreso del Consejo Europeo de Investigaciones Sociales en América Latina. Salamanca: Instituto de Iberoamérica, Universidad de Salamanca. 28 de junio al 1 de julio de 2016.

Municipio de Quilmes, Secretaría de Desarrollo Social (2015) Miradas de una gestión con perspectiva de derechos 2007 / 2015. Quilmes, Provincia de Buenos Aires: Municipalidad de Quilmes.

\section{Secretaría de Niñez y Adolescencia de la Provincia de Buenos Aires, UNICEF}

y Grupo Pharos (2015) Estudio sobre la institucionalidad del Sistema de Promoción y Protección de Derechos de Niñas, Niños y Adolescentes en los municipios de la Provincia de Buenos Aires, Buenos Aires. www.grupopharos.org/wp/estudio-sobre-la-institucionaloidad-del-sistema-de-promoción-y-protección-de-derechos-de-ninas-ninos-y-adolescentes-en-los-municipios-de-la-provincia-de-buenos-aires/ 
Soler, Graciela y Monzani, María Ana (2006) "Miradas plurales, recorridos singulares”, en Frigerio, Graciela y Diker, Gabriela (coord.) Infancias y adolescencia. Teorías y experiencias en el borde. Buenos Aires: Editorial Noveduc: 107-114.

Tilly, Charles (2000) La desigualdad persistente. Buenos Aires: Ed. Manantial.

Yin, Robert (1994) Case Study Research. Design and Methods. Thousand Oaks\& Londres: Sage Publications.

Zapiola, Carolina (2008) La ley de patronato de 1919: una reestructuración parcial de los vínculos entre Estado y "minoridad".Ponencia presentada en las Jornadas de Historia de la Infancia en Argentina: 1880-1960, UNGS-UdeSA, noviembre de 2008.

\section{Entrevistas citadas}

Ex-Subsecretario de Niñez y Adolescencia de la Provincia de Buenos Aires (junio 2014).

Ex-asesora de Ministro de Desarrollo Social de la Provincia de Buenos Aires (octubre 2013).

Ex-Jefe de Gabinete de Ministros, Municipalidad de La Matanza (mayo, 2015).

Director de Niñez y Adolescencia, Municipalidad de La Matanza (agosto, 2013).

Abogada Servicio Local, Municipalidad de La Matanza (mayo, 2014).

Ex-Secretaria de Desarrollo Social, Municipalidad de Quilmes (julio 2015).

Ex-Subsecretaria de Niñez, Municipalidad de Quilmes (septiembre 2013).

Coordinadora de proyectos territoriales, Municipalidad de Quilmes (abril 2015).

Subdirector de la UGC Castelar Sur, Municipalidad de Morón (agosto 2013).

Trabajadora social del Servicio Local, Municipalidad de de Lanús (julio, 2013).

Ex-coordinadora de una de las oficinas del Servicio Local, Municipalidad de San Martín (agosto 2013).

\section{Cómo citar este artículo:}

Moro, Javier (2018) "Diez años del sistema de promoción y protección de los derechos de la niñez y la adolescencia: un balance desde el Conurbano Bonaerense". Revista Perspectivas de Políticas Públicas, vol 8 N¹5: 107-137 